\title{
UCLA
}

Mester

Title

Conversaciones con Mario Vargas Llosa

Permalink

https://escholarship.org/uc/item/3pr5z1c5

Journal

Mester, 29(1)

Author

Mester, [No author]

Publication Date

2000

DOI

10.5070/M3291014541

Copyright Information

Copyright 2000 by the author(s). All rights reserved unless otherwise indicated. Contact the author(s) for any necessary permissions. Learn more at https://escholarship.org/terms 


\section{Conversaciones con Mario Vargas Llosa}

El 19 de Junio de 1999, Mario Vargas Llosa fue el invitado de honor con motivo de la ceremonia de graduación de la División de Humanidades de UCLA. El día anterior, tras el coloquio de la mañana (véase p.92), el novelista realizó una lectura de su obra en el Schoenberg Auditorium de UCLA. Leyó dos pasajes de novelas muy distintas: el episodio de la matanza de las vicuñas, de Lituma en los Andes, y la diatriba contra los deportes de Los cuadernos de Don Rigoberto. Tanto en la mañana como en la tarde, el público tuvo la oportunidad de dialogar con Mario Vargas Llosa sobre distintos aspectos de su obra y de su carrera. Al finalizar las sesiones públicas, tres editores de Mester y otra estudiante graduada (Soraya Alamdari, Antonieta Monaldi, Wilmer Rojas y Sylvia Blynn) tuvieron de nuevo la ocasión de entrevistar brevemente al escritor.

Las páginas que siguen condensan el diálogo público y la entrevista con Mester. Los conocedores de la obra de Mario Vargas Llosa encontrarán aquí una jugosa presentación de algunas de sus posiciones literarias y políticas, datos sobre obras específicas y acaso algunas confesiones inesperadas (sobre su preferencia retrospectiva por el teatro, por ejemplo). Los no iniciados seguramente disfrutarán descubriendo los particulares puntos de vista del autor peruano sobre su país, sobre el arte de escribir y sobre su experiencia literaria.

\section{SESIONES PUBLICAS}

Pregunta del público: Usted ha dicho que el escritor es un suplantador de Dios y que trata de crear una realidad total, que es como nuestro mundo. Cuando Ud. crea esa realidad, ¿se siente propietario de sus personajes? Por ejemplo, al final de la novela Pantaleón y las visitadoras, el capitán Pantoja es enviado a Pomata como castigo. ¿Cuál sería su opinión si alguien toma al capitán Pantoja en Pomata y continúa la novela de ahí para arriba?

Mario Vargas Llosa: Por mí puede hacer lo que quiera. No tengo ningún inconveniente... [Risas]. Primero hay que explicar esa idea del suplantador de Dios. La palabra parece un poco tremebunda, pero detrás de ella hay una idea muy sencilla. La novela no es una fotografía de la realidad, sino algo que no está en la vida. Nosotros escribimos y 
leemos novelas buscando algo que la vida no nos da. $Y$ en este sentido la novela es una especie de respuesta a la creación de Dios. El escritor de novelas es alguien que trata de alguna manera de insubordinarse contra este mundo y esta vida de una manera simbólica, enfrentándole otro mundo que ha inventado él. Es un acto de deicidio en un sentido muy simbólico, muy benigno, algo que no justificaría de ninguna manera que llevaran a los novelistas a la hoguera.

Respecto a la propiedad, es una pregunta interesante y compleja. Desdeluego que, de alguna manera, esas criaturas le pertenecen a quien las creó. Probablemente la relación de esas criaturas con su creador es la misma que la de los seres humanos con el suyo, si es que éste existe. Este creador es propietario, pero esa propiedad tiene una libertad que le permite insubordinarse contra su creador. De hecho, muchoscreadores no reconocerían a sus criaturas después de un cierto tiempo. Esas criaturas han pasado a pertenecer a los lectores, que han visto en ellas muchas cosas queel novelista jamás quiso poner, y quelas han convertido en algo muy distinto de lo que fueron en la imaginación del creador. Por otra parte, yo creo que las novelas evolucionan con la historia: leer el Quijote hoy en día no es lo mismo que leerlo en el siglo XVII o en el XVIII. El mundo, la sensibilidad, la imaginación, han cambiado y evolucionado. Leemos desde unas perspectivas emotivas, de conocimiento, de sensibilidad, que son muy diferentes de los lectores contemporáneos de Cervantes. Por tanto, vemos en el Quijote cosas que los lectores de ese tiempo no podían ver. Si una novela es lograda, representa una vida. Y la vida está siempre moviéndose. El autor ha perdido el control, y aquello ha pasado a ser propiedad de los lectores. Nosotros tenemos el derecho de adueñarnos de una novela que nos gusta, que nos habla, que nos conmueve, que nos cambia, que nos transforma... Esa novela nos da, si es rica y diversa, cosas muy diferentes. Y por tanto pasa a ser propiedad nuestra también.

\section{P: ¿Vivir fuera de su país ha afectado su identidad y su manera de escribir?}

MVLL: Me ha cambiado muchísimo el haber vivido en diferentes países, el haber conocido a gente muy diferente, de culturas diversas, el haber estado expuesto a culturas que no eran la mía... Esa experiencia me llevaba a cotejar lo que creía, lo que me gustaba o lo que me disgustaba. Todo eso tiene que haberme formado de un modo distinto a como me habría formado si no hubiera salido de mi propio país y mi propia cultura. 
Lo que no sé es hasta que punto y de qué manera esas experiencias se han reflejado en mi obra. Es algo que me intriga. Pero estoy absolutamente seguro de que yo no hubiera escrito los libros que he escrito sin haber vivido en España, en Francia, en Inglaterra, sin haber leído los libros que he leído... Uno es consciente de una manera muy relativa de sus influencias. Estoy seguro de que los escritores que admiro más, que he leído y releído más, pues habrán tenido una influencia muy grande en mi obra. Y es muy posible que autores de los que no tengo conciencia de haber recibido cosas han dejado una huella en mi obra. Esta mañana estaba escuchando a Ray Boland, y la exposición que hizo sobre Goya y mi obra; y a Fernando Iwazaki, que encontraba semejanzas, coincidencias, influencias de Nabokov en mi última novela. Ambas exposiciones me parecieron muy persuasivas. La de Goya fue una sorpresa total, pero al mismo tiempo había algo allí que me resultaba muy convincente. Nabokov es un escritor que yo siempre he admirado mucho. Sobre todo Lolita: la he leído varias veces. Es una de las grandes novelas de este siglo. Habría sido tomada mucho más en serio si no hubiera tenido el éxito que tuvo... Un éxito rodeado además demalicia, de morbo, que perjudicó mucho la comprensión estrictamente literaria de su originalidad extraordinaria. Lolita sí es muy posible que haya dejado una huella, porque es una novela que me deslumbró por la delicadeza de su artificio. Hay una estructura que bajo una apariencia dejuego, de humor, de insolencias, en realidad esconde una complejidad cultural: alusiones a obras literarias o filosóficas, al psicoanálisis... Todo esto hecho con una sutileza extraordinaria. Seguramente la impresión de esa obra tiene que haber dejado un sedimento. En general un lector, un crítico, ve eso con más claridad que el escritor mismo. Uno no siempre es consciente de sus influencias.

\section{P: ¿Qué inspiró el episodio de la matanza de las vicuñas en Lituma cn} Los Andes? La diatriba contra los deportes de Don Rigoberto en Los cuadernos de Don Rigoberto, que Ud. acaba de leer, me recordó un ensayo de Umberto Eco llamado "Las pompas del mundial". ¿Tienen alguna relación los dos textos?

MVLL: El episodio de las vicuñas está inspirado en un hecho real. Había una reserva de vicuñas en esta región en Ayacucho. Fue una de las operaciones más espectaculares de Sendero Luminoso, un grupo maoísta que operó en el Perú desde 1980 hasta relativamente hace pocos años. Provocó una enorme estupefacción, porque parecía difícil entender qué mecanismo mental había llevado a este grupo a matar a centenares de 
vicuñas. Si hay un animal inofensivo, delicado, absolutamente benigno, es la vicuña. Quizás este hecho es simbólico de los extremos de ceguera a que puede llevar el fanatismo. A mí me impresionó esta matanza y se me quedó en la memoria. Y cuando escribí esta novela en que la violencia política desempeña un papel tan importante, inmediatamente la recordé. No sé cómo ocurrió exactamente, pero el hecho es que ocurrió y que fue la fuente de inspiración para este episodio.

Leí el otro episodio [de Don Rigoberto en la sesión de lecturas de mi obra], porque decidí, junto con Efraín [Kristal], mostrar aspectos muy diversos de mi obra. La última novela, a diferencia de la anterior, es una novela más bien risueña. No hay esa seriedad casi funeral de la anterior, que es sobre la violencia. Si no se conoce el personaje, quizás no se comprende bien la vehemencia y virulencia de esta diatriba contra el deportista. El personaje principal de esa novela [Los cuadernos de Don Rigoberto], Don Rigoberto, tiene una doble vida. La civil, en la que aparece como un benigno empleado de seguros. Y en el libro hay muchas diatribas contra los aseguradores. Las escribe un director de una compañía de seguros, quien parece el hombre más conformista y aprensivo, un ciudadano aburridamente ejemplar. Hay otro Don Rigoberto, secreto, privado, que sólo se manifiesta en el seno de su hogar, a quien sólo conoce--y no integralmente-su mujer, Doña Lucrecia, de la que él dice estar enamorado. Ese otro Don Rigoberto es un rebelde radical, un anarquista que defiende la individualidad como el valor supremo, que vive aterrorizado con la idea de la desaparición del individuo en la sociedad masificada de nuestros días, y que defiende su soberanía a través de gestos puramente simbólicos: diatribas, cartas, notas que escribe en unos cuadernos que nadie lee sino él.

Al mismo tiempo ha creado un enclave en su hogar, donde trata de alcanzar esa forma perfecta de vida con la que sueña: hecha de ritos, del cuidado de las formas, de una disciplina a través de la cual se expresa la locura de la fantasía, del deseo, de la imaginación. La diatriba contra los deportes no es una diatriba contra el deporte en sí, sino contra la religión de los deportes, esa especie de comunión colectiva a través de los grandes campeonatos, en los que el mundo entero parece asumir una personalidad colectiva y funcionar como una masa puramente gregaria, entusiasmándose con las victorias o desmoralizándose con las derrotas: algo que a él lo espanta no porque desprecie la práctica de los deportes, sino porque le parece que detrás de esa masificación hay una abdicación de la soberanía y la libertad individuales. Por eso toda forma de vida gregaria, en la queel individuo se disuelve opierdeautenticidad, lo exaspera, y contra eso protesta de esta manera simbólica. 
No conocía ese texto de Umberto Eco, pero déjeme decirle que a mí los deportes no me disgustan. Por el contrario. Nunca fui muy bueno, perosiempre fui muy entusiasta: como futbolista, como nadador, como corredor, como tenista... Sí comparto algo de la indignación de Don Rigoberto ante ese enloquecimiento colectivo que producen ciertos campeonatos, períodos en los que la gente parece abdicar de toda otra preocupación o curiosidad para entregarse, como se entregaba a los espectáculos del circo la población romana. Algo que produce un cierto horror, porque parece que la sinrazón tomara el predominio de la vida y la razón quedara totalmente aplastada. Si sobre esto ha escrito Umberto Eco, pues sí comparto bastante sus alarmas.

\section{P: Cuando usted dice al final de Lituma en Los Andes: "Cortándole sus} criadillas, tajándoselas y banqueteándose como si fueran un manjar". ¿Por qué tiene que ser precisamente esa parte del cuerpo humano?

MVLL: Quizás la mejor manera de responderle es contarle por qué escribí esa historia. Para mí siempre es muy misterioso cómo surge la idea de una novela: de una manera no premeditada, muy casual. En este caso fue una conversación, muchos años antes de escribir el libro, con dos antropólogos peruanos. Ellos habían estado haciendo trabajos en comunidades del interior; no en la región donde transcurre la novela, sino en el Cuzco. Contaron que habían vivido en una comunidad, a la que habían ido y vuelto muchas veces, y con la cual creían tener una relación bastante estrecha. Un día descubrieron que esa comunidad había hecho un sacrificio humano: habían matado una persona para los dioses lares de la montaña. Esto los dejó espantados y al mismo tiempo muy sorprendidos, porque creían conocer muy bien a esta comunidad, que era más bien primitiva. (Hay otras que están modernizadas). No sospechaban que eso podía ocurrir.

Esta historia me dio vueltas en la cabeza durante muchos años. Estamos en el siglo veinte, veintiuno ya, y hay un Perú muy moderno. Pero al mismo tiempo hay un Perú secreto allí en la montaña: arcaico, religioso, irracional, donde la razón todavía no controla la vida, que puede de pronto manifestarse en hechos de esa violencia tan primitiva. En los años '80, el Perú vivió la experiencia terrible de la violencia política: hubo un Sendero Luminoso y otro movimiento más pequeño, que iniciaron operaciones terroristas: asesinatos, matanzas-algunas tan absurdas como ésta de las vicuñas-, destrucción de maquinarias, de tractores, de carreteras, de puentes... Algo que pareció un esfuerzo para hacer retroceder a un Perú que ya tenía un retraso considerable a 
un mundo pre-industrial, pre-racional. Esta violencia causó miles de muertes, despobló regiones enteras del Perú-porque la gente huía a las ciudades-: la violencia de los terroristas y también la violencia del Ejército, porque éste respondió con una brutalidad absolutamente feroz.

Una de las consecuencias desconcertantes fue una serie de incidentes o episodios que nos revelaron instituciones que creíamos totalmenteextinguidas, que resucitaban y estaban allí, vivas. Por ejemplo, los pishtacos. Es una vieja creencia de que hay unos personajes, medio humanos, medio míticos, medio diabólicos, que vienen a las ciudades a matar gente para sacarle la grasa. (En la colonia, se decía que sacaban la grasa para hacer ciertas medicinas). Lo extraordinario es que esto ocurrió nosolamente en los pueblossino en una ciudad como Ayacucho, que es una capital de Departamento. Ahí hubo verdaderos ataques colectivos de pánico. Se decía que llegaban los pishtacos a matar gente para sacarle la grasa que el gobierno iba a enviar a Washington, donde la necesitaban como combustible para los cohetes que enviaban a la luna. O se decía que era grasa con la que el Perú pagaba la deuda externa. Eso que parece tan ridículo provocó verdadero pánico. Se dice que el pishtaco es alguien racialmente distinto de los nativos: hubo casos de personas rubias o muy blancas que fueron linchadas por gente que creía que eran diablos que venían a matarla. Esto llegó a producir casos realmente muy dramáticos.

Esto me dio el material de esa novela. Dije: “Quiero escribir una novela que muestre eso: cómo en una sociedad ya moderna hay secretamente otra sociedad, otra cultura, que arranca del pasado más remoto, que nunca ha desaparecido del todo, que ha vivido clandestina, subterránea, latente, y que en razón de este cataclismo de la violencia política, de la fractura para la vida de las comunidades sobre todo del centro de los Andes, ha hecho que resuciten viejos demonios, como el terror a los pishtacos, o los sacrificios humanos".

Me costó un enorme esfuerzo escribir esta novela. Es muy difícil hacer persuasiva una historia en la cual se sacrifica a otro ser humano y además se lo come, se comulga con él... El encadenamiento que tiene para mí una ficción es siempre muy sorprendente. Yo estaba escribiéndola en Princeton. Un día, mientras trabajaba en la biblioteca en las tardes, alguien a mi lado se paró y dejó el libro abierto. Me dio curiosidad y lo hojeé. Era un libro sobre el culto de Dionisios en Grecia y en Roma. Vi una nota que decía que las fiestas [dionisiacas] se perseguían no por las borracheras, sino porque en ellas se pasaba de las borracheras a los sacrificios humanos. Esto me impresionó mucho, y 
empecé a leer sobre Dionisios. Encontré similitudes muy grandes entre el fenómeno que estaba viviendo la parte más primitiva de la sierra del Perú, y un mito clásico de la cultura occidental sobre la irracionalidad, sobre la destrucción de la razón por la sinrazón, por la pasión, por la emoción... De allí surgió la idea de darle más protagonismo al tema del sacrificio humano. Surgió también la idea de transplantar el mito de Dionisio al mundo de los Andes. Esa es, en forma muy resumida, la gestación de la historia y la razón por la que el canibalismo humano tiene un papel tan importante en la novela.

\section{P: ¿Cómo influyó su experiencia personal en La ciudad y los perros? ¿Cómo le surgió la idea de escribir Pantaleón y las visitadoras?}

MVLL: La ciudad y los perros es una novela que no habría podido escribir si no hubiera tenido la experiencia del colegio militar [Leoncio Prado]. Yo estuve ahí dos años, como cadete, y de ahí surgió la idea. Sólo traté de ser fiel al ambiente que viví en el Colegio. Pero toda la anécdota y muchos de los personajes son inventados; otros están inspirados en seres reales, pero siempre de una manera muy relativa. En una novela es imposible decir: "Este personaje es tal persona de la vida real", "Este hecho es un hecho real y éste es inventado", incluso si uno se empeña en hacerlo. Uno puede querer transplantar un hecho real a la novela, pero deja de ser real desde el momento en que es un hecho escrito, incorporado además a un contexto que lo presiona y lo modifica.

En todo lo que he hecho, siempre ha pasado lo mismo. Siempre el punto de partida ha sido una experiencia personal. Ésta no pasa de modo intangible a la novela: se transforma, se modifica, y muchas veces no estoy totalmente consciente de los cambios que la realidad novelesca imprime a la memoria.

Pantalcón resulta de dos viajes que hice yo a la selva. El año 58 fui en una expedición con un antropólogo mexicano. Hicimos un recorrido que le había organizado una antropóloga de la Universidad de San Marcos, del Instituto Lingüístico de Verano, por la región del Alto Marañon. Estuvimos en muchos pueblecitos de la Amazonia. En casi todos los lugares había muchas protestas contra los soldados de las guarniciones de frontera, que abusaban de las chicas y perseguían a las mujeres; eso creaba una tensión con los cuarteles. Volví a hacer ese mismo recorrido en el año 65, luego de haber terminado La Casa Verde, que estaba basada en muchos recuerdos del primer viaje a la selva. Allí me encontré con la segunda parte de esta historia. Los civiles seguían protestando contra los soldados pero ya no por los abusos contra las 
mujeres, sino porque los soldados recibían convoyes de visitadoras que les mandaban desde Iquitos. Las visitadoras eran una institución que había creado el Ejército, para evitar los incidentes que provocaban los soldados aislados ahí en los cuarteles. Iban en aviones y en barcos. En la población civil había rencor y resentimiento, porque decían que eso era un gran privilegio de los soldados. La historia era maravillosa porque ahíse podía ver perfectamente las dos caras de una situación. Yo no vi nunca una visitadora, pero escuché estas historias. Aprovechando mi experiencia en el Leoncio Prado, imaginé un oficial especializado en operaciones de logística al que le encargan esta misión, y ahí ya salió todo.

Es una novela a la que yo le tengo mucho cariño, porque a mí me descubrió las posibilidades del humor. Yo lo cultivaba en la vida, pero en literatura tenía la mala influencia de Sartre, que era muy inteligente, pero no hay ni una sonrisa en toda su inmensa obra. Yo creía que la literatura seria no podía ser risueña. Traté de escribir Pantaleón y las visitadoras en serio, y me fue imposible. Descubrí que hay historias que sólo se pueden contar de manera humorística y risueña. Para mí Pantaleón... significó eso: el descubrimiento del humor en literatura.

P: Antes de El clogio de la madrastra, sus novelas siempre reflejaban algún tipo de compromiso-o porlo menos preocupación-con algún tema político o social. Eso no aparece en esa novela. ¿Es casualidad que la escribió justo cuando estaba más involucrado en la campaña electoral?

MVLL: Podría ser una forma de escapismo ante la concentración en la vida política. Aunque [el tema] aparece indirectamente en la vida de Don Rigoberto, un hombre que de joven fue militante de Acción Católica y pensaba que a través de la doctrina cristiana se podía cambiar la vida, se podía mejorar la sociedad. Luego él se decepcionó profundamente, y se replegó en un mundo puramente individual de fantasía, de búsqueda del placer. Esa es también una opción, que puede ser discutible. Pero es una manera de pronunciarse, de tomar partido.

\section{P: ¿Por qué escribió un libro sobre Arguedas?}

MVLL: Hay un problema que todo escritor peruano, ecuatoriano, mexicano o boliviano siente en carne propia: sabe que hay una parte muy importante de su país que le es ajena (como yo, un escritor peruano que no sabe quechua); sabe que hay otra cultura incompatible con una 
cultura moderna y occidentalizada. Un mundo que en cambio Arguedas sí sentía con mucha lucidez y conocía muy de adentro, y que le enriqueció enormemente su fantasía, su imaginación. Es un factor que me llevó a interesarme por él. Y hay otro factor: el político. Es un problema que, en cierta forma, resulta anacrónico. En los años 50 y 60 , la política y la literatura en Latinoamérica se encontraban, se confundían, provocaban toda clase de malentendidos y problemas. La obra de Arguedas, así como su personalidad, vivieron este encuentro de una manera mucho más dramática que en el caso de otros escritores. Yo tengo la impresión de que la pureza moral de Arguedas lo llevó a escribir unos libros y a asumir unas posiciones que perjudicaron profundamente su obra de creación, que hubo en el un sacrificio moral de su vocación o de sus inclinaciones de escritor, para responder a unas presiones que se ejercitaron enormemente sobre él y que eran fundamentalmente políticas, no literarias. Es un hecho que siempre me intrigó y me entristeció en Arguedas. Es lo que el libro quiere tratar de explicar: el esfuerzo inmenso que significó para él escribir, por ejemplo, Todas las sangres, que yo creo un gran fracaso, en el sentido de que detrás [de esta novela] hay un gigantesco esfuerzo para escribir un libro de acuerdo a lo que se esperaba de él, a lo que un mundo muy motivado políticamente exigía del escritor peruano que sabía quechua, que había sido un indio, que había compartido la condición trágica del sector más explotado de la sociedad peruana. Todo eso me fascinó mucho y es lo que está detrás de ese ensayo.

P: En su libro La utopía arcaica, Ud. expresa su admiración por José María Arguedas. ¿Por qué su preferencia hacia él, y no hacia otros escritores como César Vallejo, que algunos dirían que es, no mejor, pero sí más famoso que Arguedas?

MVLL: No hay por qué contraponerlos. Uno puede admirar mucho a Arguedas y a Vallejo al mismo tiempo. Yo digo en el prólogo de La utopía arcaica que José María Arguedas es probablemente el único escritor peruano con el que yo he llegado a tener una relación muy entrañable, como con autores que me han marcado profundamente, como Flaubert o Faulkner. ¿Por qué? Eso uno mismo no lo puede explicar. ¿Por qué se enamora uno de una mujer y no de otra? ¿Por qué detesta a una persona al apenas conocerla y no a otras? Antes expliqué algunas de las razones por las que el caso Arguedas es, para cualquier escritor peruano, un caso que lo remueve íntimamente. Es un personaje muy dramático, un escritor muy interesante. Creo que fue muy irregular, que escribió algunas cosas muy bellas y algunas muy malas, pero incluso las malas 
tienen un sentido muy trágico, porque representaron un sacrificio, una inmolación en nombre de una ética, de una moral. Eso hizo que yo leyera y releyera la obra de Arguedas con mucha devoción. Eso no impide que admire mucho a Vallejo, que admire mucho a César Moro y a otros escritores peruanos.

P: Como usted sabe, la viuda de Arguedas ha sido una prisionera política en su país, en condiciones inhumanas, por muchos años. Dos presidentes chilenos viajaron al Perú para pedir su extradicción, pero no tuvieron éxito. ¿Cuál es su opinión sobre esta violación de los derechos humanos en el Perú hoy día?

MVLL: Me plantea Ud. un problema delicado. No puedo responder en dos palabras. La viuda de Arguedas colaboró con Sendero Luminoso; fue una militante muy activa. Las acciones de Sendero Luminoso a partir de 1980 han causado muchísimas catástrofes en mi país. Sin su terrorismo, sin la inseguridad que creó, probablemente jamás hubiera habido un golpe de estado y hoy Perú sería una democracia, no la dictadura disimulada que es.

La participación de alguien en un movimiento terrorista es absolutamente reprobable y condenable. Miles de inocentes murieron a consecuencia de las acciones de Sendero Luminoso; sobre todo gente humilde, como los campesinos, que fueron el $90 \%$ de las víctimas. De tal manera que una persona que colaboró con Sendero Luminoso no es una persona inocente, ni muchísimo menos. Es una persona que tiene una enorme responsabilidad en la muerte de por lo menos 30 mil personas, en la destrucción de un sistema democrático y en las violaciones de los derechos humanos que el establecimiento de una dictadura ha significado en el Perú.

Es fundamental reconocer esto antes de hacer cualquier crítica a la situación de la justicia en el Perú. Estas críticas, desde luego, son perfectamente legítimas: en el Perú hay una dictadura, no hay un sistema de justicia. Sibila Arredondo [la viuda de Arguedas] ha sido juzgada en unas condiciones que son inadmisibles dentro de cualquier sociedad mínimamente democrática. Es el caso no sólo de Sibila Arredondo, sino de todos los que han sido juzgados por tribunales militares en el Perú: [se usan] jueces enmascarados, voces deformadas por aparatos electrónicos, sin posibilidad de apelar o de que los abogados conversen siquiera con sus clientes... Desde luego eso es una caricatura de justicia, y contra eso hay que protestar. Yo lo he hecho desde el mismo instante en que ocurrió el golpe de estado en el Perú. Pero creo que singularizar el caso de Sibila Arredondo porque es viuda de un 
escritor famoso, hacer campañas como si realmente se tratara de una persona inocente y excepcional, es absolutamente inaceptable. Hay miles de personas en el Perú que están en las cárceles y han pasado por los tribunales militares, y muchas de ellas no tuvieron ningún tipo de colaboración con Sendero Luminoso: son inocentes. No conozco las acusaciones contra Sibila Arredondo, pero sí su participación clara, explícita, manifestada además en múltiples oportunidades, en una organización terrorista que mató inocentes y que está detrás de la destrucción de la democracia en el Perú. Es muy importante cuando se protestan los abusos que se siguen cometiendo en el Perú contra los derechos humanos. También hay que dejar muy claro el tipo de responsabilidad de personas como Sibila Arredondo en lo que está pasando en el Perú desde 1992.

\section{P: Cuando Ud. lanzó su candidatura a la presidencia en las elecciones del 90, dijeron en unos programas cómicos que Mario Vargas Llosa, como presidente, sería buen escritor. ¿Ha pensado usted en relanzarse como candidato?}

MVLL: Lo que he dicho y sigo diciendo es que participé en política activa y profesional por unas circunstancias muy excepcionales, no como una vocación política. La política me ha interesado simpre, desde joven, pero como un intelectual, como un debate, como un ejercicio de la crítica, como participación en la vida cívica en tanto que ciudadano. Además descubrí mi vocación en una época en que era inconcebible separar la actividad intelectual y literaria de un cierto compromiso cívico. Esas fueron las ideas de los existencialistas franceses, de Sartre, que impregnaron toda la vida intelectual en los 50 y 60 , los años en que yo fui estudiante universitario y publiqué mis primeras cosas. A la idea del compromiso cívico he seguido siendo fiel toda mi vida. Ya pasó de moda. Pero para mí un cierto compromiso, una participación en el debate cívico, siguen siendo inseparables del trabajo intelectual.

La vocación política es algo muy distinto. Es una vocación por el poder, por la acción política... Algo que yo nunca tuve y que me forcé a tener en los años en que fui candidato. Seguramente una de las razones - aunque no la única-por las que perdí las elecciones, es que no se puede ser un buen político si uno no se compromete profundamente con esa actividad. Yo hice lo posible por comprometerme, pero evidentemente lo hice muy mal. De tal manera que soy muy consciente de haber sido muy mal político, muy mal candidato.

\section{P: La actividad del escritor...}


MVLL: Del escritor no diría yo, porque hay escritores que son muy buenos políticos. Usted piensa en Václav Havel, que es muy buen escritor y muy buen político, y ha prestado un gran servicio a su país. Hizo una gran labor como resistente, y luego, en la transición hacia la democracia, desempeñó un papel político de primera categoría. Ennobleció la política con ideas, con discursos que realmente iban a la razón... Hay escritores que son buenos políticos, y hay los que somos malos políticos, como en mi caso. Fue una experiencia puramente transitoria, que quedó allí. Desde luego, no me desolidarizo de ella. Pero quedó atrás. Luego de terminada he vuelto a lo que es realmente mi vocación y mi trabajo, y a participar en la vida política como un intelectual que opina pero que no piensa hacer carrera política.

\section{ENTREVISTA CON MESTER}

MESTER: El libro sobre Trujillo es su segunda novela que no está ambientada en el Perú. ¿Ha cambiado su método de trabajo al tener que hacer tanta investigación histórica?

MVLL: Nonecesariamente, porque he trabajado comocon otras novelas mías. Claro, por tratarse de una novela basada en un hecho histórico, he tenido que hacer muchísima investigación. Pero también la hice con $L a$ guerra del fin del mundo, que también estaba basada en un hecho histórico. La he hecho no porque quiera ser absolutamente fiel a la historia. Es una novela escrita como La gucrra del fin del mundo, tomándome todas las libertades que, según creo, tiene derecho a tomarse un novelista. Pero para fantasear e imaginar con conocimiento de causa, sabiendo exactamente lo que se puede conocer de la historia de los últimos años de Trujillo y lo que ocurrió inmediatamente después de su muerte. Sigo las grandes líneas de la historia, pero trabajando con la fantasía. Hay muchos personajes y episodios inventados, e incluso algunos episodios históricos son tratados con mucha libertad. Es una novela que tiene un contex to histórico, pero no es una historia disfrazada de novela.

MESTER: ¿Ud. usa técnicas narrativas dentro de sus textos dramáticos?

MVLL: No creo que hay una diferencia esencial. El teatro es mucho más visual, mucho más oral; el diálogo es mucho más importante; las descripciones prácticamente no existen. Esas son las diferencias obvias. Pero en cuanto a la estructura, la organización del tiempo, los personajes, 
los puntos de vista, las técnicas se confunden. El teatro es una forma de ficción, exactamente como la novela. Consiste en la creación de una realidad aparte. En un caso sobre todo a base de la palabra; en otro, a través del diálogo y el movimiento. Pero es la creación de un mundo aparte, soberano, auténtico, que debe ser autosuficiente y tener en sí todos los ingredientes necesarios para ser comprendido. Yo no veo una cesura, un abismo, entre el teatro y la novela.

MESTER: ¿Se pueden aplicar, por ejemplo, la caja china, la muda...?

MVLL: La caja china, sin ninguna duda. En La scĩorita de Tacna es evidente: es una historia que va saliendo de la memoria, y cuenta historias dentro de historias. En Katic y el hipopótamo es clarísimo que hay unas cajas chinas que transladan la historia no solamente del presente al pasado, sino de la realidad a la pura imaginación. Ahí se hace fundamentalmente a través de diálogos, y no a través de descripciones o de narración. Pero también los paralelismos, los vasos comunicantes... En las obras que he escrito hay mucho de esa técnica de unir escenas que tienen que ver con espacios, con tiempos diferentes. En mi caso no hay una diferencia esencial entre lo que es la técnica teatral y la técnica novelesca.

MESTER: Ahora que esta trabajando en su novela sobre Trujillo, quisiera saber cuál es la diferencia entre una obra en borrador y la novela terminada.

MVLL: La obra en borrador es muy incierta, una obra donde falta la coagulación. Para mí un borrador es una especie de magma dentro del cual está la historia, como está una estatua dentro de un bloque de granito: hay que ir puliendo y debastando hasta que la figura realmente toma su forma. Un borrador es ese bloque de granito, donde uno sabe que está la novela, pero hay que llegar a ella, sobre todo eliminando. Yo corto mucho, reescribo, reedito, reestructuro. Esa es la parte que me gusta más, la que hago con más entusiasmo y más seguridad. En cambio la primera versión siempre me cuesta mucho trabajo; sobre todo me da mucha inseguridad, sin saber muy bien adónde voy. Hasta que no tengo el borrador no sé muy bien por dónde va a ir la novela. Aunque tengo una idea general al principio, la idea definitiva la tengo sólo cuando la novela está terminada.

MESTER: ¿Y todavía experimenta inseguridad, después de cuarenta años como escritor? 
MVLL: Siempre. Yo creo que en un trabajo de tipo creativo nunca se llega a tener una seguridad absoluta. Bueno, quizás algunos escritores la tengan. Pero yo tengo la misma inseguridad de cuando escribí mis primeros cuentos. Ahora sé que con el trabajo, con la disciplina, rehaciendo todo poco a poco, la novela va tomando forma. Era mucho más inseguro si iba a terminar o no la historia cuando empecé a escribir. Pero sobre todo en la primera parte del trabajo, sí siento la misma y quizás más inseguridad que cuando era joven.

MESTER: Acaba de mencionar la disciplina y el trabajo. Paris Reviczv, tras muchos entrevistas con escritores consagrados, ha descubierto una característica común: casi todos trabajaban con horario de burócrata. ¿Ud. se describiría de la misma manera?

MVLL: Yo trabajo de una manera muy disciplinada. Nopodría terminar una novela si no trabajara con una continuidad, con unos horarios muy rigurosos. Trabajo todos los días mañana y tarde. En la mañana trabajo en mi casa y en las tardes siempre trabajo en una biblioteca. Me gusta cambiar de ambiente. Trabajo de lunes a sábado en el libro que estoy escribiendo. Los domingos escribo artículos. A veces los viajes perturban esa disciplina. Si son viajes muy cortos, tengo que interrumpir, y después me cuesta mucho retomar lo que estoy haciendo. La disciplina ha sido fundamental para mí; ha sido lo que en realidad me ha permitido escribir.

MESTER: ¿Cuántas horas al día trabaja?

MVLL: Generalmente empiezo a las diez de la mañana, y hasta las dos de la tarde trabajo en mi casa. Son mis horas más creativas. Luego trabajo en las bibliotecas otras cuatro horas. Eso es más elástico porque ahí leo, tomo notas, corrijo, a veces escribo o reescribo. El trabajo de documentación siempre lo hago en las tardes, nunca en las mañanas. Pero digamos que trabajo unas ocho horas al día como promedio.

MESTER: ¿Cómo elige Ud. el género?

MVLL: Yo no elijo el género. Las historias vienen con su género a cuestas. Yo sé, cuando tengo la historia, si esa historia es para el escenario o es una novela. Por ejemplo, con El loco de los balcones yo siempre pensé que era una obra de teatro. ¿Por qué? No lo sé. Pero sentí, como lo sentí con La señorita de Tacna y Ojos bonitos ${ }_{L}$ cuadros feos, que esas 
historias podían aprovecharse mucho mejor a través de una forma teatral que a través de una novela. Pudiera ser que veo esas historias de una manera mucho más visual que las otras. Oque tienen una dimensión que las hace mucho más teatrales. Pero eso lo digo con beneficio de inventario, porque no estoy seguro. Lo que sí: la seguridad no me falla nunca cuando tengo la historia. Es como si las historias vinieran con una etiqueta que dijera: "Yo soy para el teatro. No soy para la novela".

\section{MESTER: ¿Lo sabía con La huida del Inca también?}

MVLL: A mí siempre me gustó mucho el teatro. Era lo que más me gustaba. Si en el Perú hubiera habido una vida teatral rica, tal vez yo hubiera sido sobre todo un escritor de teatro. Pero no había. Yo escribí esta obra cuando estaba todavía en el colegio, muy chiquito, y tuve el placer de verla representada. Pero era my difícil escribir teatro sin la esperanza de que se representara, porque casi no había un movimiento tetral. Escribí cuentos y novelas, pero siempre me ha gustado mucho el teatro; era una tentación que siempre estaba ahí. Y un día, pensando en esta tía-abuela mía, la mamá Elvira, sentí desde el primer momento que era una obra de teatro. Era una historia que yo vi a través de esta viejecita siempre sentada en un sillón, viviendo un mundo completamente extinto, el mundo de su infancia, desaparecido hacía cincuenta o sesenta años, totalmente desconectada de la vida contemporánea. Para mí era una figura absolutamente teatral. No sabría decir con absoluta certeza por qué tengo esa seguridad de que ciertas historias son mejores para el teatro que para la novela. Pero nunca he vacilado respecto al género.

MESTER: ¿Conoció Udd. personalmente al protagonista del Loco de los balcones?

MVLL: Sí, yo lo conocí al personaje, que era muy conmovedor: el Dr. Bruno Roselli, un viejecito que parecía casi de caricatura porque era muy delgadito, medio encorvado... Caminaba como un muñeco, muy enérgico. Incluso seguí unas conferencias de historia del arte que dio en la Universidad de San Marcos. Lo que me fascinó del personaje fue su campaña para salvar los viejos balcones coloniales de la picota, cuando estaban derribando casas antiguas para construir edificios. Él hizo esta campaña quijotesca...

MESTER: ¿En los 50? Y Ud. lo escribió en los 80. 
MVLL: Sí, yo lo escribí muchos años después. Pero eso no es raro. Por lo general yo vivo los temas de las novelas muchos años antes de escribirlas. Por ejemplo, la idea de escribir esta novela de Trujillo me vino en el año 75, cuando pasé ocho meses en la República Dominicana. Y la empecé a escribir tantos años después. Lo mismo con la historia de Bruno Roselli, que debe haber ocurrido cuando yo estaba en la universidad, en el 53 ó 54 . Siempre me quedó la imagen de este viejecito haciendo esa campaña en las calles. Se convirtió en un "folk hero", una especie de héroe popular. Fracasó, porque los balcones los derribaron igual. Pero ese gesto quijotesco, generoso, inspirado sólo por el amor que tenía por esas viejas construcciones, me quedó en la memoria.

MESTER: Ud. firmó un ejemplar [del Loco de los balcones] en Berlín en febrero del 92. Pero la obra salió primero en Londres, en la BBC.

MVLL: Sí, claro. Salió primero en una versión radial muy bonita que hizo la BBC. La edición [del 92] está muy reformada; no es la versión original de la radio, que es del 88. [La obra] se estrenó en inglés, en el teatro The Gate, en una versión bastante buena con un magnífico actor. Nunca se ha dado en español.

\section{MESTER: ¿Tiene otro proyecto de texto dramático?}

MVLL: Siempre tengo muchos. Nunca me han faltado. Hace años que tengo un proyecto de monólogo de Santa Teresa. Desde que yo leí su autobiografía, quedé muy fascinado por dos cosas: por un lado, su amor a las novelas de caballerías, que yo compartí de joven; y por otro, por esa decripción como angustiada, como misteriosa, de cuando empieza a oír las voces. A mí eso me parece lo más teatral del mundo: el momento en que empieza a escuchar esas voces se siente intimidada, desconcertada. Es un testimonio maravilloso. Desde esa época yo sentí que eso debía ser un monólogo teatral. Es uno de los proyectos de teatro que tengo. A ver si tengo vida para terminarlo.

MESTER: En La utopía arcaica, Ud. habla sobre el dilema del escritor latinoamericano entre el compromiso político y la vocación literaria. Se ve que es un problema que Ud. ha tenido que vivir. Pero hoy comentó [durante la mesa redonda] que el problema político era ya un anacronismo. ¿Se refería a que ya no existe?

MVLL: No, el problema existe. Lo que ocurre es que la gran mayoría de los escritores en los años 50 ó 60, pensaba que formaba parte de la 
responsabilidad intelectual participar de alguna manera en el debate político: comprometerse, opinar, ejercer la crítica. Hoy en día, en cambio, hay una gran mayoría de escritores que piensa que la literatura no debe contaminarse de política, que el escritor debe concentrarse en su trabajo, que las preocupaciones políticas no tienen nada que ver con la literatura, y que incluso pueden ser un obstáculo para desarrollar la riqueza y perfección que exige una obra de arte.

La idea del compromiso literario, tal como fue desarrollada por Sartre y su generación de escritores franceses (Camus, etc.), hoy es considerada anacrónica por las nuevas generaciones. No es mi manera de pensar. Yo creo que un escritor debería participar, en la medida de sus posibilidades, en la vida cívica. No afiliándose a partidos políticos si no quiere hacerlo, manteniendo su independencia. Creo que un escritor (sobre todoen países como el Perú o los países latinoamericanos, donde todavía hay tantos problemas que resolver, donde la vida política es tan precaria y a veces tan mediocre) debería contribuir con ideas, ayudando a buscar soluciones, o por lo menos ayudando a definir los problemas. Eso no es incompatible con el ejercicio de la literatura. Incluso no es malo que la litera tura tenga un contacto con la problemática viva. Cuando se aparta de ese tipo de preocupaciones puedeconvertirse en una actividad muy artificial, dejar de alimentarse de la experiencia común.

MESTER: En Cartas a un joven novelista, Ud. ofrece muchos consejos generosos a los escritores jóvenes. ¿Cómo ve el futuro de la literatura latinoamericana? ¿Hay escritores realmente buenos, que van a ayudar al público internacional a conocer a autores no sólo del boom, sino de esta nueva generación?

MVLL: Creo que la literatura está muy viva en América Latina. Están constantemente apareciendo nuevos escritores. Quizás uno de los fenómenos más interesantes de los últimos años ha sido la aparición de escritoras: poetas, novelistas que han surgido de un extremo a otro del continente y que han alcanzado un público, un reconocimiento.

Tampoco sigo tanto la actualidad como para saber cuáles son los mejores o los peores. Mis lecturas están muy condicionadas por mi propio trabajo: los tres últimos años he estado leyendo sobre todo historia y literatura dominicanas. Pero en general soy optimista sobre la situación de la literatura en América Latina. Me parece que hay una nueva generación de escritores y hay un público. Se está editando mucho más, lo cual indica que se está leyendo mucho más que antes: un síntoma de muy buena salud. 